\title{
A SOLUBLE, DYE-LABELLED CHITIN DERIVATIVE ADAPTED FOR THE ASSAY OF KRILL CHITINASE
}

\author{
Reinhard Saborowski* $\dagger$, Friedrich Buchholz*, Ralf-Achim H. VetTer*, \\ STEPHAN J. WiRTh $\ddagger$ and Gerhard A. Wolf $\ddagger$ \\ *Institut für Meereskunde an der Christian-Albrechts-Universität, Düsternbrooker Weg 20, D-2300 \\ Kiel 1, Germany (Tel. 0431-5973938; Fax 0431-565876); and §Institut für Pflanzenpathologie und \\ Pflanzenschutz der Georg-August Universität, Grisebachstra Be 6, D-3400 Göttingen, Germany \\ (Tel. 0551-393724; Fax 0551-394187)
}

(Received 5 November 1992; accepted 8 January 1993)

\begin{abstract}
Carboxymethyl-Chitin-Remazol Brilliant Violet (CM-Chitin-RBV) was used for a colorimetric assay of chitinase activity in Antarctic krill, Euphausia superba. Comparison with a reductimetric method by end-product detection was carried out by measuring FPLC elution profiles of krill crude extracts with both assays. Both profiles matched significantly.

2. Krill chitinase was highly specific to CM-Chitin-RBV. The assay was characterized by easy handling and a very high sensitivity compared to that of end-product detection. Hydrolysis of CM-Chitin-RBV by $N$-acetyl- $\beta$-D-glucosaminidase, $\beta$-glucosidase, $\beta$-galactosidase and $N$-acteyl-muraminidase was negligible.

3. The enzyme characteristics of chitinase from Antarctic krill using CM-Chitin-RBV were: $\mathrm{pH}_{\mathrm{opt}}=7.5$, $T_{\text {opt }}=50-55^{\circ} \mathrm{C}, E_{\mathrm{a}}=52.1 \mathrm{~kJ} \cdot \mathrm{mole}^{-1}, K_{\mathrm{M}}=0.07 \pm 0.01 \mathrm{mg} \cdot \mathrm{ml}^{-1}$.
\end{abstract}

\section{INTRODUCTION}

Chitin (poly- $N$-acetyl- $\beta$-D-glucosamine) is one of the most abundant organic materials in nature, and this is particularly so in marine environments where chitin is the dominant material of crustacean exoskeletons. Chitin also occurs in spines of some centric diatoms (Montgomery et al., 1990). As a result of its chemical composition (carbon and nitrogen in a ratio of 8:1), chitin has a high nutritive value. Consequently, it is of ecological importance in both the carbon and the nitrogen cycle.

The role of chitin in nutrient cycles should not only be elucidated by the determination of the amount of present chitin but should also include a measurement of the chitinolytic degradation potential.

Chitin can be degraded by bacteria, fungi and also by many invertebrates and vertebrates (Jeuniaux, 1966). High activities of chitinolytic enzymes are present in the stomach and integument of Euphausia superba and Meganyctiphanes norvegica, where they act as digestive and moulting enzymes, respectively (Buchholz, 1989; Saborowski and Buchholz, 1991). We also found chitinolytic activity in Euphausia triacantha, the isopod Serolis polita and the Antarctic salp Salpa tompsoni (unpublished data). SpindlerBarth et al. (1990) investigated chitinolytic enzymes in Palaemon serratus.

Natural degradation of chitin to $N$-acetyl- $\beta$-Dglucosamine (NAG) is performed by a two-

†Present address: Biologische Anstalt Helgoland, Meersstation, D2192 Helgoland, Germany (Tel. 04725819 322; Fax 04725819369 ). enzyme system consisting of an endochitinase (poly- $\beta ; 1,4 ;(2$-acet-amido-2-deoxy)-D-glucoside gluconohydrolase = chitinase, EC 3.2.1.14) and an exochitinase $(N$-acetyl- $\beta$-D-glucosaminidase $=$ NAGase, EC 3.2.1.29). The endochitinase hydrolyses the chitin to oligomers, mainly dimers (Powning and Irzykiewicz, 1965), which are subsequently degraded to aminosugars by NAGase.

NAGase activity can be measured easily and rapidly using the artificial substrate $p$-nitrophenyl- $N$ acetyl- $\beta$-D-glucosaminide (Kimura, 1974). In contrast, the measurement of endochitinase is more complex. The most commonly used methods are the detection of the end-product aminosugars (reductimetric assay) according to Morgan and Elson (1934) as modified by Boden et al., (1985), and the degradation of tritiated chitin as a substrate (Molano et al., 1977). However, these methods require long incubation times (up to $24 \mathrm{hr}$ ) or large-scale laboratory equipment. They are not suitable for rapid and easy detection of a large number of samples.

Wirth and Wolf (1990) developed the soluble, dye-labelled substrate CM-Chitin-RBV for the detection of endochitinase of microbial origin. It consists of carboxymethylated chitin (Trujillo, 1968; Hirano, 1988) labelled covalently with Remazol Brilliant Violet 5R. Because of high sensitivity and low costs it is of interest for routine procedures.

In our study we investigated the application of CM-Chitin-RBV for the detection of crustacean chitinase. The linearity of the assay with increased enzyme amounts and incubation times was determined. Furthermore, fractions of FPLC elution profile of an 
Euphausia superba crude extract were tested and the activity pattern was compared to that determined by the end-product measurement according to Boden et al. (1985). The substrate specificity of other hydrolases such as NAGase, $\beta$-glucosidase, $\beta$-galactosidase and $N$-acetyl-muraminidase was compared to that of chitinase, using CM-Chitin-RBV. Finally, enzyme characteristics of Euphausia superba chitinase, such as $\mathrm{pH}-$ and temperature optimum, activation energy and $K_{\mathrm{M}}$-values, were determined.

\section{MATERIAL AND METHODS}

\section{Origin of samples}

Specimens of Antarctic krill, Euphausia superba, were caught west of the Antarctic Peninsula $\left(61^{\circ} \mathrm{S} 44^{\prime} 9557^{\circ} \mathrm{W} 53^{\prime} 80\right)$ during the cruise $11 / 4$ (21.12.1989-18.01.1990) of the research vessel FS Meteor. Sampling was done using a Rectangular Midwater Trawl RMT $1+8$ (Roe and Shale, 1979). Mesh width of the RMT was $4.5 \mathrm{~mm}$ and operation depth was from $60 \mathrm{~m}$ to the surface.

The samples were frozen immediately after the catch and maintained at $-80^{\circ} \mathrm{C}$ during transfer to Kiel, Germany, where they were stored at the same temperature until analysis in July 1990.

\section{Extract preparation}

Extracts for FPLC were carried out on whole animals in $2 \mathrm{ml} 0.2 \mathrm{M} \mathrm{Na}$-citrate-phosphate buffer (CPB), pH 5.5 per $\mathrm{g}$ animal by homogenization on ice using an Ultra-Turrax (Janke \& Kunkel, TP 18/10). Homogenization times were $3 \times 15 \mathrm{sec}$, each interrupted by a break of $20 \mathrm{sec}$. After centrifuging $\left(80,000 \mathrm{~g}, 30 \mathrm{~min}, 4^{\circ} \mathrm{C}\right.$, Christ Omikron) the supernatants were desalted and rebuffered to $0.1 \mathrm{M}$ Imidazole-HCI buffer, pH 6.8, using Sephadex G25PD10 columns (17-0851-01; Pharmacia, Uppsala, Sweden). Finally, extracts were filtered $(0.45 \mu \mathrm{m}$, Schleicher \& Schüll, FP 030/2). For the detection of enzyme characteristics, extracts of krill thoraces were prepared. The abdomen, the anterior region of the cephalothorax, including the eyes, and the pereiopods were removed. The remaining material was coarsely chopped, transferred to $1.5 \mathrm{ml}$ reaction caps (Eppendorf, 3810) and CPB, pH 5.5, was added in the ratio $1: 2$. Because of the small volume here homogenization was performed by sonication on ice (Bronson Sonifier B12, microstick 101-148-063) for $3 \times 15 \mathrm{sec}$ at $30 \mathrm{~W}$, interrupted by $20 \mathrm{sec}$ pauses. After centrifuging $(15,000 \mathrm{~g}$, Heraeus Biofuge A) supernatants of two to three samples were pooled to provide a sufficient volume for the analytical series.

Investigation of the $K_{\mathrm{M}}$-value of krill chitinase were performed on homogenates of the stomach and the midgut gland (hepatopancreas) separately. Both organs were removed from deep frozen animals and homogenized in a total volume of $1 \mathrm{ml} 0.2 \mathrm{M}$ CPB by sonication as described above. Centrifuging was carried out at $15,000 \mathrm{~g}$ for $10 \mathrm{~min}$ (Heraeus, Biofuge A).

\section{Chromatography}

Extracts were fractionated by Fast Protein Liquid Chromatography (FPLC, Pharmacia) using a prepacked Q-Sepharose HP column (16/10, Pharmacia, 17-1064-01). The extracts were applied to the column at a rate of $3 \mathrm{ml} \cdot \mathrm{min}^{-1}$. Elution was effected by a gradient from 0 to $0.85 \mathrm{M} \mathrm{NaCl}$ in $0.1 \mathrm{M}$ Imidazole- $\mathrm{HCl}$ buffer, $\mathrm{pH}$ 6.8. Per run, 95 fractions were collected with a volume of $4.3 \mathrm{ml}$ each. Tubes containing the fractions were cooled on ice. Enzyme analysis was performed on each second fraction.

\section{Analysis of enzyme activity}

Chitinase activity by end-product detection was determined reductimetrically according to Boden et al. (1985) as modified by Spindler and Buchholz (1988) using purified crustacean chitin.

Chitinase activity with CM-Chitin-RBV as substrate was essentially carried out as described by Wirth and Wolf (1990), but applied to $1.5 \mathrm{ml}$ reaction tubes (Eppendorf, 3810) with the following modifications: $200 \mu 10.2 \mathrm{M}$ CPB, $\mathrm{pH} 6.0$ was added to $100 \mu 1$ of an aqueous solution of CM-Chitin-RBV (2 $\mathrm{mg} \cdot \mathrm{ml}^{-1}$, Loewe Biochemica $\mathrm{GmbH}$, Otterfing, Germany). After pre-incubation for $5 \mathrm{~min}$ at $35^{\circ} \mathrm{C}$ the enzymatic reaction was started by adding $100 \mu 1$ of enzyme solution. Following $30 \mathrm{~min}$ of incubation at the same temperature, the reaction was stopped by adding $100 \mu 1$ of $1 \mathrm{~N} \mathrm{HCl}$. The reaction caps were cooled in an ice-water bath for at least $10 \mathrm{~min}$ to ensure complete precipitation of the non-degraded substrate at $\mathrm{pH}<3.0$ After centrifuging $(15,000 \mathrm{~g}$, $5 \mathrm{~min}$; Heraeus Biofuge A) the absorbance of the supernatant was measured photometrically at $550 \mathrm{~nm}$ against air, in duplicate. Blanks were run in parallel for which enzyme and $\mathrm{HCl}$ were added, simultaneously.

NAGase activity was detected by degradation of the artificial substrate $p$-nitrophenyl- $N$-acetyl- $\beta$-Dglucosaminide $=$ pNpNAG (Sigma, N-9376), as previously described by Spindler (1976) and Spindler and Buchholz (1988). In alkaline media, the released $p$-nitrophenol developed a yellow colour which was measured photometrically at $410 \mathrm{~nm}$ against air. The incubation time was $15 \mathrm{~min}$ at $35^{\circ} \mathrm{C}$. Using $5-\mathrm{ml}$ reaction tubes, $50 \mu 1$ of enzyme solution was added to $50 \mu 10.2 \mathrm{M} \mathrm{CPB}, \mathrm{pH} 5.5$. After preincubation, the reaction was started by adding $50 \mu \mathrm{l}$ of a $0.3 \%(\mathrm{w} / \mathrm{v})$ solution of pNpNAG in $0.2 \mathrm{M}$ CPB, pH 5.5. The reaction was terminated by adding $2.5 \mathrm{ml}$ of $0.01 \mathrm{M}$ $\mathrm{NaOH}$. Samples were run in duplicate with a parallel blank.

$\beta$-Glucosidase was detected by a two step assay using a $1 \%(w / v)$ solution of salicine (2-[hydroxymethyl]phenyl- $\beta$-D-glucopyranoside; Sigma, S-0625) in $0.2 \mathrm{M} \mathrm{CPB}, \mathrm{pH} 5.5$. Incubation was carried out for $60 \mathrm{~min}$ at $35^{\circ} \mathrm{C}$ with $450 \mu \mathrm{l}$ of this salicine solution 
and $50 \mu \mathrm{l}$ of enzyme solution. The reaction was stopped by heating for $10 \mathrm{~min}$ at $100^{\circ} \mathrm{C}$. Blanks were run in parallel with the heat-degraded enzyme. After centrifuging $(15,000 \mathrm{~g}, 5 \mathrm{~min}$; Heraeus Biofuge $\mathrm{A})$, $100 \mu 1$ of the supernatant was removed for glucose determination using a glucose UV-test (Böhringer, 716251).

\section{Specificity}

In order to confirm the specificity of krill chitinase to CM-Chitin-RBV, incubation assays were performed with commercial enzyme preparations of chitinase, $\beta$ - $N$-acetyl-glucosaminidase, $\beta$-glucosidase, $\beta$-galactosidase and $N$-acetyl-muraminidase (all Sigma). Activities given by the producers were recalculated for each enzyme as $1 \mathrm{U}=1 \mu \mathrm{mol}$ substrate degradation $\cdot \mathrm{min}^{-1}$.

In the case of chitinase, one unit of activity was described as releasing of $1 \mathrm{mg}$ NAG from chitin within $48 \mathrm{hr}$. The activity was calculated by measuring reducing sugars (Sigma, personal communication). This reported activity was recalculated as a molar turnover of $1.569 \mathrm{nmol} \cdot \mathrm{min}^{-1}$ and thus as $1.569 \mathrm{mU}$ instead of $1 \mathrm{U}$.

In the case of $N$-acetyl-muraminidase it was not possible to apply the producer's activity definition to the common unit definition because the activity was defined as increase of absorption at $600 \mathrm{~nm}$ per min while degrading cell walls of Streptomyces faecalis.

The assays were run in quadruplicate according to the method for chitinase detection, using CM-Chitin$\mathrm{RBV}$ as reported in the present paper. The activities of enzymes applied, expressed in common unit definitions, were $2.5 \mathrm{U} \cdot \mathrm{ml}^{-1}$ (Chitinase, EC 3.2.1.14), 0.25 and $0.5 \mathrm{U} \cdot \mathrm{ml}^{-1}$ (NAGase, EC 3.2.1.29), 5.0 and $2.5 \mathrm{U} \cdot \mathrm{ml}^{-1}(\beta$-glucosidase, EC 3.2.1.21), 12.5 and $25.0 \mathrm{U} \cdot \mathrm{ml}^{-1}(\beta$-galactosidase, EC 3.2 .1 .23$) . N$ acetyl-muraminidase was applied with 125 and $250 \mathrm{U} \cdot \mathrm{ml}^{-1}$ (here, the activity description was used according to the producer).

\section{Enzyme characteristics}

The assays described as follows were carried out in $1.5 \mathrm{ml}$ reaction caps (Eppendorf, 3810) with $50 \mu \mathrm{l}$ of crude extract, $250 \mu 1$ of buffer and $100 \mu 1$ of an aqueous solution of CM-Chitin-RBV $\left(2 \mathrm{mg} \cdot \mathrm{ml}^{-1}\right)$.

The $\mathrm{pH}$ dependence of krill chitinase activity was measured using CPB $(0.2 \mathrm{M})$ for the range pH 3.0-7.5 and borate buffer (Boden et al., 1985) for pH 8.0-12.0. Incubation temperature was $35^{\circ} \mathrm{C}$ and the incubation time was $30 \mathrm{~min}$.

The temperature-dependence was measured within the range of $0-70^{\circ} \mathrm{C}$ at $\mathrm{pH} 6.0$, using $0.2 \mathrm{M}$ CPB.

Thermal stability measurements were carried out on preincubated enzyme solutions $(60 \mathrm{~min})$ in the range $0-60^{\circ} \mathrm{C}$. The subsequent assays were run at $35^{\circ} \mathrm{C}$ for $30 \mathrm{~min}$ in $0.2 \mathrm{M} \mathrm{CPB}, \mathrm{pH} 6.0$.

Activation Energy $\left(E_{\mathrm{a}}\right)$ for krill chitinase was calculated from the data of the thermal optimum curves, applying the Arrhenius equation.

$K_{\mathrm{M}}$-values of stomach and midgut gland extracts were measured using substrate concentrations of $0.025,0.0375,0.045,0.0575,0.065,0.0825,0.125,0.25$ and $0.5 \mathrm{mg} \cdot \mathrm{ml}^{-1} \mathrm{CM}-\mathrm{Chitin}-\mathrm{RBV}$. Incubation was carried out for $30 \mathrm{~min}$ at $35^{\circ} \mathrm{C}$ and $\mathrm{pH} 6.0(0.2 \mathrm{M}$ CPB).

\section{RESULTS}

\section{Linearity of the assay}

The investigations showed a linear increase of activity with respect to enzyme concentration up to an absorbance of 0.500 at $550 \mathrm{~nm}$. Above 0.5 the curve became non-linear (Fig. 1a), probably due to limiting substrate concentrations. Furthermore, a linear relationship was demonstrated between incubation time and absorbance (Fig. lb).

\section{Elution profiles}

The elution profiles of krill chitinase were determined with both assays, using CM-Chitin-RBV and the reductimetric assay. In order to obtain an optimal comparison of both assays, each of the data sets of measured activities was averaged. The single values were then recalculated in relation to this average (Fig. 2).

Both profiles showed a high grade of correspondence. In both cases, the first activity peak eluted
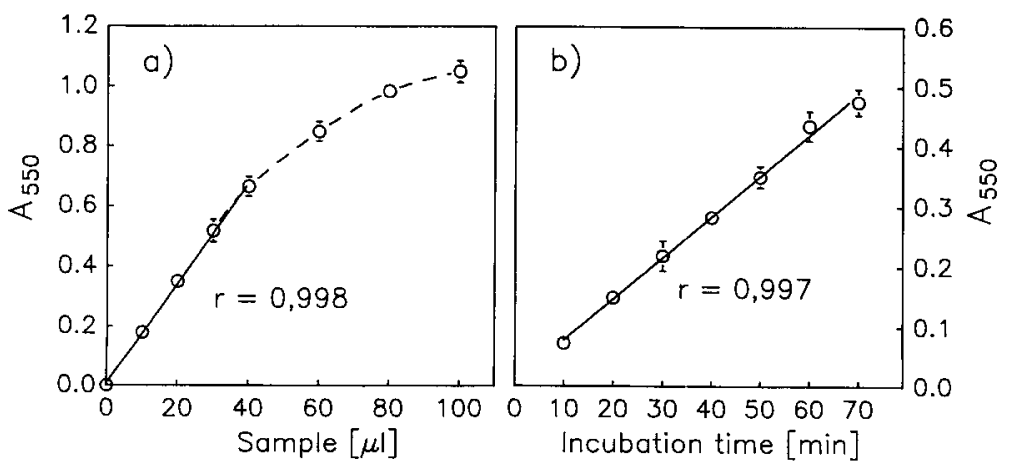

Fig. 1. Linearity of the chitinase assay using CM-Chitin-RBV as substrate. Error bars represent SD $(N=3)$. (a) Hydrolysis of CM-Chitin-RBV as a function of crude extract concentration. (b) Hydrolysis of CM-Chitin-RBV as a function of incubation time. 
between fractions 30 and 40 where the $\mathrm{NaCl}$-gradient was $0.1-0.25 \mathrm{M}$. A further broad activity peak was detected between fraction 55 and 85 ( NaClgradient $=0.5-0.75 \mathrm{M}$ ). Within fractions $40-55$, the activity profiles showed slight differences. While the chitinase activities measured by end-product detection remained nearly constant, with a slight decrease from fraction 40 to fraction 50 , the activity detected using CM-Chitin-RBV as substrate showed a peak in fraction 48 (Fig. 2).

In order to obtain a statistical comparison of these data, an analysis of regression was performed.

The regression parameters and the correlation coefficient, including all measured fractions were:

$$
\begin{aligned}
y=0.943 x+3.322, \quad r=0.865 & \\
& P<0.001(N=35) .
\end{aligned}
$$

The parameters, excluding fractions $39-53$, were calculated as:

$$
\begin{aligned}
& y=0.999 x-1.377, \quad r=0.946, \\
& P<0.001,(N=24) .
\end{aligned}
$$

\section{Specificity investigations}

In order to test possible interactions with other hydrolases that cleave $\beta$-glycosidical links, elution profiles of $N$-acetyl- $\beta$-D-glucosidase (NAGase) and $\beta$-glucosidase were determined. However, no distinct activity peaks were found for these enzymes within the fractions $40-55$ (results not shown), indicating no influence on CM-Chitin-RBV hydrolysis.

Additionally, the hydrolysis of CM-Chitin-RBV by NAGase, $\beta$-glucosidase, $\beta$-galactosidase and mutanolysin ( $N$-acetyl-muraminidase) was investigated. Based on a standardized unit definition, the highest turnover of CM-Chitin-RBV was found using chitinase, and was set to be $100 \%$. NAGase and $\beta$-glucosidase caused a turnover of 0.06 and $0.12 \%$, respectively, compared to that of chitinase. No degradation of CM-Chitin-RBV could be observed using $\beta$-galactosidase and mutanolysin.

\section{Enzyme characteristics of krill chitinase}

$p H$-optimum. The activity of crude extracts of $E$. superba incubated with CM-Chitin-RBV showed a

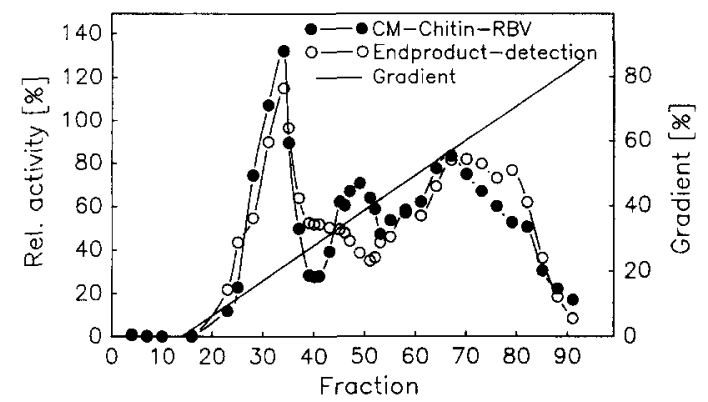

Fig. 2. Chitinase FPLC elution profiles of a crude extract of $E$. superba using the method by end-product detection and CM-Chitin-RBV as substrate.

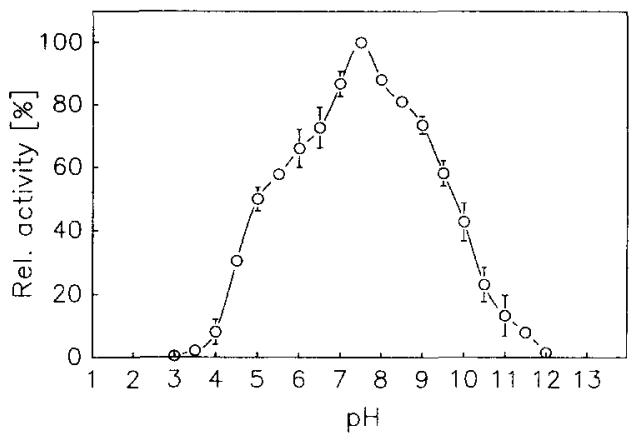

Fig. 3. pH dependence of chitinase activity in crude extracts of $E$. superba. Within the range of $\mathrm{pH} 3.0-7.5 \mathrm{CPB}(0.2 \mathrm{M})$, and between $\mathrm{pH} 8.0$ and 12.0 borate buffer was used. Incubation: $30 \mathrm{~min} ; 35^{\circ} \mathrm{C}$. Error bars represent $\mathrm{SD}(N=3)$.

distinct maximum at $\mathbf{p H} 7.5$ (Fig. 3). Fifty percent of maximal activity occurred at $\mathrm{pH} 5.0$ and 10.0. Lowest activity was observed at $\mathrm{pH} 3.0$ and $\mathrm{pH} 12.0$.

Temperature optimum and thermal stability. The highest chitinase activity was found between 50 and $55^{\circ} \mathrm{C}$. Between 0 and $45^{\circ} \mathrm{C}$ the activity increased exponentially. Above $55^{\circ} \mathrm{C}$, a sharp activity decrease led to minimal activity at $70^{\circ} \mathrm{C}$ (Fig. 4). Krill chitinase showed a high thermal stability (Fig. 4). Up to a preincubation temperature of $40^{\circ} \mathrm{C}$ and a preincubation time of $60 \mathrm{~min}$, the activity decreased only slightly, and did not sink below $90 \%$ of the initial activity at $0^{\circ} \mathrm{C}$. Above $45^{\circ} \mathrm{C}$, a sharp decrease of activity occurred. At a preincubation temperature of $60^{\circ} \mathrm{C}$, only $4 \%$ of the initial activity remained.

Activation energy. The Arrhenius plot showed two different linear dependencies, between 0 and $20^{\circ} \mathrm{C}$ and 20 and $50^{\circ} \mathrm{C}$, respectively (Fig. 5). The calculated activation energy for the first range was $128.5 \mathrm{~kJ} \cdot \mathrm{mole}^{-1}$ and for the second range $\left(>20^{\circ} \mathrm{C}\right)$ $52.1 \mathrm{~kJ} \cdot \mathrm{mole}^{-1}$.

Kinetic properties. Krill chitinase was characterized by typical Michaelis-Menten kinetics. The $K_{\mathrm{M}}$-value was at $0.07 \pm 0.01 \mathrm{mg} \mathrm{CM}$-Chitin-RBV $\cdot \mathrm{ml}^{-1}(N=5)$. Up to a concentration of $0.5 \mathrm{mg}$ CM-Chitin$\mathrm{RBV} \cdot \mathrm{ml}^{-1}$ no inhibition of activity was detected. A

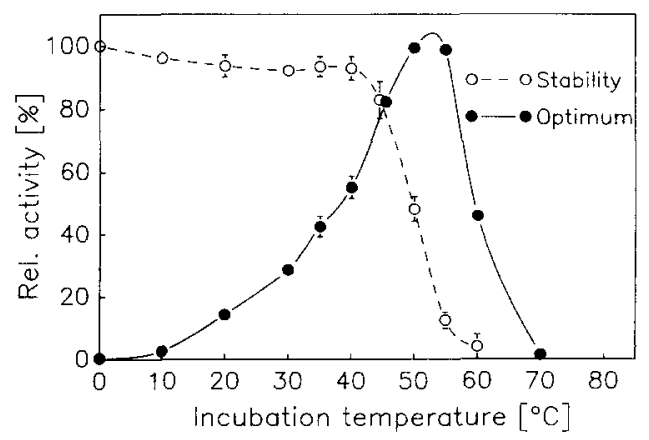

Fig. 4. Temperature dependence of chitinase activity and thermal stability of krill chitinase, using CM-Chitin-RBV as substrate. Incubation: $30 \mathrm{~min} ; \mathrm{pH} 6.0 ; 0-70^{\circ} \mathrm{C}$. Thermal stability was detected after preincubation of extracts for $60 \mathrm{~min}$. Error bars represent SD $(N=3)$. 
typical curve of activity of midgut gland chitinase is shown in Fig. 6 (including the Lineweaver-Burk plot). Separate extracts of the stomach and the midgut gland of the krill gave identical results.

\section{DISCUSSION}

An advantage of the reductimetric chitinase determination by end-product detection, according to Morgan and Elson (1934), exists in the incubation of the enzyme sample with natural chitin (e.g. purified crustacean chitin). In this way, unspecific reactions that might occur by incubation with an artificial substrate can be avoided. However, this water-insoluble chitin can only be added as a suspension to the incubation medium. As a consequence, the effectiveness of the hydrolysis depends on particle size and the nature of the surface of the chitin substrate. The reductimetric assay requires permanent stirring and long incubation times (up to $24 \mathrm{hr}$ ). Furthermore, the resulting oligomers must be degraded to aminosugars (by $\beta$-glucosidase or exochitinase) in a subsequent incubation step which prolongs the procedure and increases the risk of experimental error.

In order to develop an alternative for the detection of chitinase activity Hackman and Goldberg (1964) performed a modification of chitin by covalent dyelabelling. After enzymatic hydrolysis, water-soluble oligomers were detected photometrically in the supernatant of the incubation medium. However, an available commercial chitinase substrate based on this method gave variable and thus unsatisfactory results, when applied in our laboratory.

In contrast, the application of a soluble substrate ensures a more complete hydrolysis by the enzyme and increases the sensitivity of the procedure. A water-soluble derivative of chitin is effectively obtained by carboxymethylation (CM-Chitin), according to Trujillo (1968) and Hirano (1988).

The substrate CM-Chitin-RBV we used here was previously described in detail by Wirth and Wolf (1990) and combines both modifications mentioned above: it is also covalently linked with Remazol Brilliant Violet-5R as water-soluble. The high sensi-

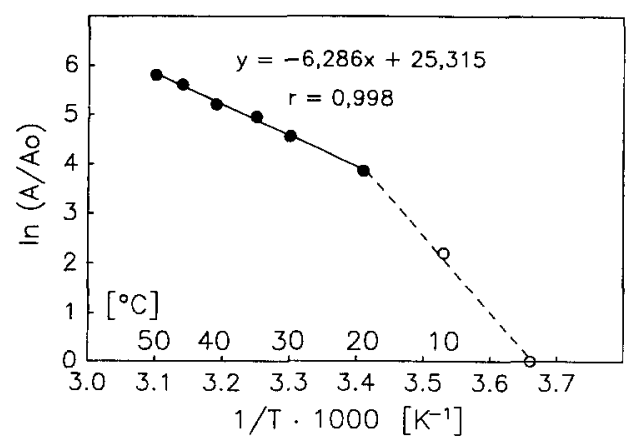

Fig. 5. Arrhenius plot of krill chitinase calculated from data of temperature activity profiles. Regression parameters relate to temperatures higher than $20^{\circ} \mathrm{C}$.

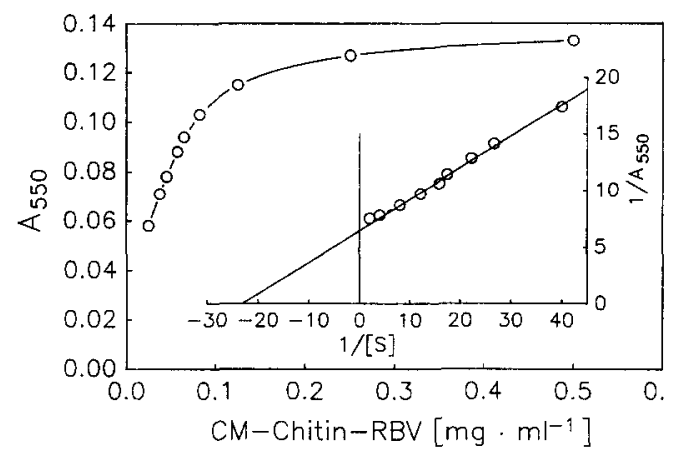

Fig. 6. Michaelis-Menten kinetic and Lineweaver-Burk plot of krill chitinase (midgut gland) using CM-Chitin-RBV.

tivity of the assay reduced the required incubation times in our investigations to $30 \mathrm{~min}$ and proved to be reliable and easy to handle. With increasing enzyme concentrations and incubation times, the chitinase of Euphausia superba showed linearity of measurements over a sufficient range of absorbance.

The direct comparison of the reductimetric assay was carried out on a FPLC elution profile of Euphausia superba crude extracts. The almost congruent curves demonstrated good agreement of both test procedures, despite the very different nature of the substrates used. The differences found between fractions 39-52 may indicate an unspecific reaction with other enzymes. However, NAGase and $\beta$-glucosidase did not interfere with the chitinase test. Neither $\beta$-galactosidase nor $N$-acetyl-muraminidase hydrolysed CM-Chitin-RBV. Hence, the variation reported remains to be explained.

Spindler and Buchholz (1988) reported an activity optimum at pH4.5 using end-product detection. Here, the pH-optimum of the krill chitinase assay was found at $\mathrm{pH} 7.5$. The difference is probably due to different properties of the substrates: CM-ChitinRBV precipitates at high $\mathrm{H}^{+}$concentrations (Wirth and Wolf, 1990). This effect was also used to terminate the enzyme reaction (by addition of $1 \mathrm{~N} \mathrm{HCl}$ ). The instability of the substrate can be observed in detail when CM-Chitin-RBV is incubated without enzyme at different $\mathrm{pH}$ values, i.e. in the range of $\mathrm{pH} 3.0-4.5$. Accordingly, the $\mathrm{pH}$ profile reflects the property of the substrate instead that of the enzyme at low $\mathrm{pH}$ values. The increase of the $\mathrm{OH}^{-}$concentration did not affect the assay.

Precipitation of CM-Chitin-RBV can also occur when using buffers of high concentration. Well-suited for this assay were CPB (0.2 M), pH 6 (this work) and $50 \mathrm{mM}$ sodium acetate buffer, $\mathrm{pH} 5.0$, as well as other common buffers ( $50 \mathrm{mM}$ ) in the $\mathrm{pH}$ range 4-8 (Wirth and Wolf, 1990).

The temperature optimum between 50 and $55^{\circ} \mathrm{C}$ was only slightly higher than that reported by Spindler and Buchholz (1988). However, a basically different course of activity was observed at low temperatures: the assay of the end-product detection showed an activity of $20 \%$ at $0^{\circ} \mathrm{C}$ followed by a sharp 
activity increase, reaching $50 \%$ of the maximal activity at $22^{\circ} \mathrm{C}$. In comparison, the assay with $\mathrm{CM}$ Chitin-RBV showed very low activity at $0^{\circ} \mathrm{C}$. With higher incubation temperatures, the activities increased more slowly. Fifty percent of activity was reached at $38^{\circ} \mathrm{C}$. Also in this case a specific property of CM-Chitin-RBV became noticeable. The substrate-viscosity probably increased at low incubation temperatures or the substrate did not reach its entire solubility. The enzyme was denaturated in both assays at about 40 and $45^{\circ} \mathrm{C}$, respectively.

The Arrhenius plot was divided into two linear parts. For the low temperature range, the resulting activation energy was $128.8 \mathrm{~kJ} \cdot \mathrm{mol}^{-1}$ and much higher than that of the upper temperature range $\left(52.6 \mathrm{~kJ} \cdot \mathrm{mol}^{-1}\right)$. Neither value corresponds to the uniform Arrhenius plot and activation energy of $27.6 \mathrm{~kJ} \cdot \mathrm{mol}^{-1}$ reported by Spindler and Buchholz (1988), carried out on krill chitinase by end-product detection. Here, the turnover of substrate at low temperatures probably decreased due to incomplete solution, as reported above. In contrast, maximal solubility is reached at temperatures above $20^{\circ} \mathrm{C}$, resulting in a lower value of $E_{\mathrm{a}}$.

The investigation of the kinetic properties showed a typical Michaelis-Menten curve. In contrast to NAGase from Euphausia superba (Buchholz and Vetter, 1990) and NAGase from Meganyctiphanes norvegica (Spindler and Buchholz, 1988), the chitinase reaction was not inhibited at higher substrate concentrations. The average $K_{\mathrm{M}}$-value of $0.07 \mathrm{mg}$ CM-Chitin-RBV $\cdot \mathrm{ml}^{-1}$ was very low compared to results reported by Spindler and Buchholz (1988). For chitinase from $M$. norvegica these authors found values of 1.6 and $5.2 \mathrm{mg}$ chitin $\cdot \mathrm{ml}^{-1}$, respectively, using end-product detection. The lowered half-saturation concentration measured here could also be explained by the different characteristics of the soluble substrate compared to that of crystalline chitin. The soluble substrate is better available for enzymatic attack compared to insoluble chitin which can only be attacked from the surface. Accordingly, the affinity of the enzyme to the soluble substrate may be increased and the apparent $K_{\mathrm{M}}$-value thus lowered.

Summarized, the chitinase assay using CM-ChitinRBV is distinguished by high sensitivity and easy handling. A satisfactory application of CM-ChitinRBV as a substrate for the detection of krill endochitinase activity can be carried out over the range of optimal temperature and $\mathrm{pH}$ conditions.

However, for comparative investigations of ecophysiological parameters, dealing with extreme pHvalues and low temperature, other chitinase detection methods are recommended.
Acknowledgements-We are grateful to Dipl. Biol. Jutta Heimann (Institute of Forest Botany, University of Göttingen) who initiated contact between both working groups and Dr Rory Wilson (Institute for Marine Research, Kiel) for correcting the English. This work was supported by a grant from the German Research Council (DFG Bu 548/2).

\section{REFERENCES}

Boden N., Sommer U. and Spindler K.-D. (1985) Demonstration and characterization of chitinases in the Drosophila $K_{\mathrm{c}}$ cell line. Insect Biochem. 15, 19-23.

Buchholz F. (1989) Moult cycle and seasonal activities of chitinolytic enzymes in the integument and the digestive tract of the Antarctic krill, Euphausia superba. Polar Biol. 9, 311-317.

Buchholz F. and Vetter R.-A. (1990) Enzyme kinetics in cold water' studied on chitin degrading enzymes of the Antarctic krill, Euphausia superba. Verh. Dtsch. Zool. Ges. 83, 527.

Hackman R. H. and Goldberg M. (1964) New substrates for use with chitinases. Analyt. Biochem. 8, 397-401.

Hirano S. (1988) Water-soluble glycol chitin and carboxymethylchitin. In Methods in Enzymology (Edited by Wood W.-A. and Kellogg S. T.), Vol. 161, pp. 408-416. Academic Press, New York.

Jeuniaux C. (1966) Chitinases. In Methods in Enzymology (Edited by Nuffield E. F. and Ginsberg V.), Vol 8, pp. 644-650. Academic Press, New York.

Kimura S. (1974) The $\beta-N$-acetylglucosaminidase of Bombyx mori L. Comp. Biochem. Physiol. 49B, 345-351.

Molano J., Duran A. and Cabib E. (1977) A rapid and sensitive assay for chitinase using tritiated chitin. Analyt. Biochem. 83, 648-656.

Montgomery M. T., Welschmeyer N. A. and Kirchman D. L. (1990) A simple assay for chitin: application to sediment trap samples from the subarctic Pacific. Mar. Ecol. Prog. Ser. 64, 301-308.

Morgan W. T. J. and Elson L. A. (1934) A colorimetric method for the determination of $N$-acetylglucosamine and $N$-acetylchondrosamine. Biochem. J. 28, 988-995.

Powning R. F. and Irzykiewicz H. (1965) Studies on the chitinase system in bean and other seeds. Comp. Biochem. Physiol. 14B, 127-133.

Roe H. S. J. and Shale D. M. (1979) A new multiple rectangular midwater trawl (RMT $1+8 \mathrm{M}$ ) and some modifications to the Institute of Oceanographic Sciences, RMT 1 + 8. Mar. Biol. 50, 283-288.

Saborowski R. and Buchholz F. (1991) Induction of enzymes in the digestive tract of the Antarctic krill, Euphausia superba. Verh. Dtsch. Zool. Ges. 84, 422.

Spindler K.-D. and Buchholz F. (1988) Partial characterization of chitin degrading enzymes from two euphausiids, Euphausia superba and Meganytiphanes norvegica. Polar Biol. 9, 115-122.

Spindler K.-D. (1976) Initial characterization of chitinase and chitobiase from the integument of Drosophila hydei. Insect Biochem. 6, 663-667.

Spindler-Barth M., van Wormhoudt A. and Spindler K.-D (1990) Chitinolytic enzymes in the integument and midgut-gland of the shrimp Palaemon serratus during the moulting cycle. Mar. Biol. 106, 49-52.

Trujillo R. (1968) Preparation of carboxymethylchitin. Car bohydr. Res. 7, 483-485.

Wirth S. J. and Wolf G. A. (1990) Dye-labelled substrates for the assay and detection of chitinase and lysozyme activity. J. Microbiol. Meth. 12, 197-205. 